\title{
El pasado presente del futuro. Exploraciones de las relaciones entre escuela e historia reciente
}

\author{
The Present Past of the Future. A Survey on the Relations Between School and \\ Contemporary History
}

O passado presente do futuro. Exploracoes das relaçóes entre escola e história recente

\author{
(iD Jorge Rolland \\ cronosytopoi@gmail.com \\ Instituto de Investigaciones Sociales de América \\ Latina. Facultad Latinoamericana de Ciencias Sociales. \\ CONICET, Argentina
}

Recepción: 05 Abril 2021

Aprobación: 09 Junio 2021

Publicación: 01 Diciembre 2021

Cita sugerida: Rolland, J. (2021). El pasado presente del futuro. Exploraciones de las relaciones entre escuela e historia reciente. Aletheia, 12(23), e110. https://doi.org/10.24215/18533701e110
Resumen: El estudio de los trabajos escolares de la memoria viene renovándose desde hace años gracias a la comprensión de las especificidades de los sentidos propios elaborados por los sujetos. Este enfoque aspira a vincular los fundamentos teóricos de esos trabajos y su desempeño práctico, en aras de una caracterización más realista y de la contribución a la prevención (el popularmente conocido como nunca más). Para ahondar en esta línea, se propone aquí un análisis de cinco entrevistas en profundidad realizadas a estudiantes secundarios en dos escuelas de La Plata en 2018, con los objetivos generales de delinear sus sentidos propios en relación con su cotidianidad (y no sólo con preceptos y mandatos) y explorar los intercambios e implicaciones prácticas entre los aspectos cognitivos, éticomorales y emocionales. Para ello me he centrado en las múltiples relaciones entre distintas temporalidades, inspirado por el concepto de conciencia histórica. He apreciado la divergencia entre interpretación y justificación, la influencia de distintos factores y tramas de relaciones de la cotidianidad escolar y el despliegue de complejos intercambios entre pasado, presente y futuro para afrontar una situación hipotética, con decisivas implicaciones teóricas para una educación emancipadora.

Palabras clave: Enseñanza de la historia, Representaciones sociales, Conciencia histórica, Historia reciente, Jóvenes.

Abstract: Research on school activities about the memory of the recent past has long been inspired by understanding the specificities of subjects' own constructed meanings. Thi approach aims at linking theoretical principles and practical performance in these works, in order to characterize them realistically and contribute to prevention: the so-called nunca más (never again) motto. To this end, five in-depth interviews with students from La Plata high-schools carried out in 2018 are analyzed, with an aim to define the students' selfconstructed meanings regarding their everyday life at school, beyond general precepts and mandates, and to explore the exchanges and practical implications in cognitive, moral-ethical and emotional aspects. Therefore,I have focused on the relations among different temporalities, on the basis of the concept of historical consciousness. I have assessed the divergence between 
interpretation and justification, the influence of several factors and their relations in everyday school life, and the unfolding of complex exchanges between past, present, and future to face a hypothetical situation, with significant theoretical implications for an emancipating education.

Keywords: History teaching, Social representations, Historical consciousness, Contemporary history, Youth.

Resumo: $\mathrm{O}$ estudo dos trabalhos escolares da memória está se renovando ha já anos graças à compreensão das especificidades dos sentidos próprios elaborados pelos sujeitos. Neste enfoque se pretende a vinculação dos fundamentos teóricos desses trabalhos e seu desempenho prático, no interesse de uma caracterização mais real e da contribuição para a prevenção (popularmente conhecido como "nunca mais"). Para aprofundar nessa linha, se propõe uma análise de cinco entrevistas em profundidade feitas com estudantes do ensino médio em duas escolas de La Plata em 2018, com os objetivos gerais de delinear seus sentidos próprios em relação com a sua cotidianidade (e não só com preceitos e mandatos) e pesquisar nos intercâmbios e implicaçóes práticas entre os aspectos cognitivos, éticos, morais e emocionais. Para isso, tenho focado nas múltiplas relações entre as diferentes temporalidades, inspirado pelo conceito de consciência histórica. Apreciei a divergência entre interpretação e justificação, a influência dos diversos fatores e tramas de relações da cotidianidade escolar e a implantação de intercâmbios complexos entre o passado, o presente e o futuro para enfrentar uma situação hipotética, com importantes implicações teóricas para uma educação emancipadora.

Palavras-chave: Ensino da história, Representações sociais, Consciência histórica, História recente, Jovens.

\section{INTRODUCCIÓN ${ }^{1}$}

En los últimos años, las investigaciones sobre los abordajes del pasado reciente en las escuelas de la Argentina han tendido a insistir en una dimensión más práctica que la que se venía considerando, atendiendo principalmente a los sentidos propios que construyen los sujetos en los trabajos de la memoria. Por ejemplo, en lo que toca específicamente a estudiantes, se ha incidido en la conciencia histórica (De Amézola y Cerri, 2018; Garriga et al., 2018), con un acento especial en las implicaciones o vínculos que ésta pueda presentar con relación al desempeño de aquéllos como ciudadanos y ciudadanas, sobre todo en torno a la política (Kriger, 2008, 2014; Garriga et al., 2010; De Amézola, 2018a).

El enfoque no es nuevo. Ya T.W. Adorno abanderaba un "viraje al sujeto" y contemplaba la "educación para la emancipación” como un trabajo sobre la "economía psíquica” para neutralizar el "potencial totalitario" de las sociedades contemporáneas, para "que Auschwitz no se repita" (1998, pp. 25, 28, 79, 80-1). En el contexto del Cono Sur, el pionero proyecto Memoria colectiva y represión apuntaba esta cuestión (Jelin y Lorenz, 2004, pp. 8-9), que uno de sus autores calificó como "el gran agujero negro de los estudios sobre la memoria”, referido a las y los estudiantes (Lorenz, 2006, p. 124).

Algunos trabajos trataron en fechas tempranas el asunto de la conciencia histórica en relación con el pasado reciente argentino (Mariño, 1999; Pereyra, 2007) y otros han ido teniendo en cuenta el papel de los sujetos al explorar los discursos y prácticas docentes (González, 2014), las representaciones sociales de estudiantes 
(VVAA, 2015; Zysman, 2015; De Amézola, 2018a y b), los manuales escolares (Born, 2010), las prácticas escolares en general (Pappier, 2016) y la transmisión (Raggio, 2014, 2017; Legarralde, 2017; para un repaso más detenido ver Rolland, 2020a).

En estas investigaciones aflora a menudo una queja respecto de la "discrepancia entre lo prescripto y su realización" (Raggio, 2014, p. 138), debida precisamente, en gran medida, a la indiferencia, en la teoría y en la práctica, frente a los significados, intereses, valores y anhelos de los sujetos (individuales y colectivos) (también Jelin y Lorenz, 2004, p. 4; Lorenz, 2006, p. 280; Cerri y De Amézola, 2007, p. 36).

Consciente de este problema y con el fin de contribuir a la pedagogía de la memoria en la escuela (o educación para la emancipación), en este artículo me propongo reducir esas discrepancias estudiando las relaciones significativas que entablan los sujetos con el pasado reciente y las implicaciones que pueden tener aquéllas en sus vidas. Para ello, analizo las elaboraciones de estudiantes a partir de cinco entrevistas en profundidad realizadas en dos escuelas de La Plata en 2018. El recorte temporal, correspondiente a los procesos históricos en torno a la dictadura de 1976-1983, se justifica porque es el que habitualmente se considera en estas investigaciones y porque ofrece múltiples aspectos propicios para esa pedagogía, aunque bien podrían contemplarse otros que pueden resultar más significativamente recientes para las y los estudiantes (véase, por ejemplo, Kriger 2008).

\section{Fundamentos TEÓRICOS}

En muchas de las investigaciones citadas, procedentes de diversas disciplinas, la exploración de las relaciones entre escuela e historia reciente no reside tanto en analizar el tipo y grado de comunicación y adquisición de contenidos, como en determinar qué representa su transmisión en contextos específicos (Guelerman, 2001, p. 43; Legarralde, 2017, pp. 19-20), o, desde el punto de vista del análisis sociocultural, cómo median agentes y narraciones históricas (Wertsch, 1998, pp. 50-7).

Para ello, una vía fructífera de indagación consiste en dar cuenta de la compleja articulación entre los terrenos cognitivo, ideológico (incluida la ética y moral), afectivo y estético. No se busca evaluar cómo se transmite el qué, cómo y porqué de los sucesos, sino cómo se entreteje ese conocimiento con la práctica social de los sujetos, incluyendo diversos aspectos de esos terrenos y sus implicaciones prácticas. En este sentido, el concepto de representaciones sociales es muy apropiado, pues alude a un "conocimiento pra\#ctico del mundo", en el que convergen conocimientos, valores, afectos y emociones (Castorina, 2006, pp. 77-9), que, al mismo tiempo, sirve "a los individuos [para] orientarse en su mundo social y material, y dominarlo" (Duveen y Lloyd, 2003, pp. 29-30).

Un aspecto crucial de esta intersección de dimensiones es el juego de temporalidades propio del concepto de conciencia histórica. De acuerdo con J. Rüsen (2007), implica una elaboración en torno a las tensiones entre pasado, presente y futuro, y moviliza la percepción y la interpretación, pero también la orientación y la motivación para la acción. Este autor se interesa por los procesos mentales que van constituyendo específicamente la historiografía (cosa que denomina "metahistoria", en línea con H. White, o "historiología", con J.G. Droysen), pero en términos globales se refiere a un proceso de "generación de sentido histórico" que está estrechamente vinculado con las "necesidades culturales de las actividades humanas", o sea, con la "vida práctica", de modo que el "pensamiento histórico" en general ofrece un "marco para la orientación" que vincula distintas temporalidades (pp. 194-5, 198). Nada de eso implica que ese marco sea inmutable ni que se asuma una indiferenciación anacrónica de esas temporalidades.

Todo ello supone para mí concretamente entender la historia como problema: no se trata sólo de una realidad pretérita, sino de su relación con diversos tiempos (previos, coetáneos y posteriores), además de espacios (físicos, sociales, simbólicos...), así como con proyectos, más o menos sistemáticos, para la acción (Chesneaux 1984; Hobsbawm 1997: 37-55; Fontana 1999). Cualquier narración histórica, en las dos dimensiones que vamos a distinguir aquí: la interpretativa (descripción y explicación de la historia) y la 
justificativa (justificación y valoración de su abordaje), contiene intercambios y elaboraciones sobre esas temporalidades, que entrañan soluciones particulares a los problemas históricos.

Por ello, me propongo analizar los sentidos propios de los y las estudiantes en relación con su desempeño cotidiano (y no sólo con preceptos y mandatos) y explorar los intercambios e implicaciones prácticas entre los aspectos cognitivos, ético-morales y emocionales. El primer objetivo permitiría conocer y reivindicar el papel central (aunque no siempre primordial, como veremos) de la escuela en los trabajos de la memoria, como complejo de relaciones que influye activamente en el despliegue material de esos trabajos y sus propósitos. El segundo no sólo daría cuenta de diversas dimensiones en estos trabajos, sino que abordaría cuestiones cruciales, como los principios y actitudes políticas de los sujetos, para la construcción y afianzamiento democráticos.

Centrar el estudio en las memorias de los estudiantes y hacerlo localmente no implica ignorar sus vínculos con contextos más amplios, esto es, con el campo de las memorias sociales (por ejemplo, Kriger, 2011 y, en el marco de mi propio trabajo, Rolland, 2020b: pp. 26-7, fig. 4), como tampoco supone perder de vista las complejas relaciones con la historiografía del tiempo presente (Franco y Levin, 2007), sobre algunos de cuyos aspectos (sobre todo en lo que toca a la interpretación) vuelvo al final. Por lo demás, parto de que esas memorias no entrañan ningún vínculo esencial con el pasado reciente, sino procesos sociales complejos y cambiantes, en los que se van construyendo históricamente las representaciones sobre él, como los caracterizó, en el terreno de las políticas públicas, Ana Guglielmucci (2013).

\section{METODOLOGÍA Y CARACTERÍSTICAS DE LA INVESTIGACIÓN}

La herramienta fundamental para esta investigación han sido las entrevistas en profundidad, que son típicamente dialógicas, pues crean situaciones productoras de sentido (y no tanto medios para extraer información), en el marco de una relación social y de otros elementos contextuales sobre los que es preciso reflexionar (Hammersley y Atkinson, 1994, pp. 168-9; Alonso et al., 2008). Su necesidad se ha hecho patente en el campo de la enseñanza de la historia (Carretero y Kriger, 2006, pp. 33; Legarralde, 2012; De Amézola, 2018a, pp. 36, 40-1).

Las entrevistas se llevaron a cabo, al hilo de una investigación de corte etnográfico más amplia, en dos escuelas de La Plata: una privada, católica (Escuela 1), y otra pública (Escuela 2), perfectamente parangonables, ya que se ubican en el mismo sector de la ciudad, en el interior del Cuadrado o centro, y tienen un alumnado de origen socioeconómico similar (clases medias). La primera es considerada de "élite" y la segunda sigue respondiendo a un imaginario platense de "buena escuela" de tradición normalista. Los y las estudiantes procedían de dos grupos de $6^{\circ}$ de Secundario de la orientación de Ciencias Sociales, y se los seleccionó porque ofrecían marcados contrastes en distintos sentidos (no sólo en su apreciación de la historia reciente): en el caso de la Escuela 1, Ana, que llevaba la voz cantante en un grupo particular de alumnas, suponía un contrapunto a Diego y Luca, cuyas posturas en los debates de clase sobresalían y parecían congeniar bastante con las de la docente, mientras en la Escuela 2 Justo representaba al alumno implicado y aceptado por la mayoría, incluido el docente, frente a Dona, mucho más reservada y aparte de los demás. ${ }^{2}$ Las entrevistas se realizaron en julio y agosto de 2018 , después de que se abordaran en las clases los contenidos concernidos, y duraron un promedio de 60 minutos. $^{3}$

Sus resultados se relacionan con lo que revelan otras herramientas, como las observaciones en aula, los debates conjuntos, las producciones escritas y el análisis de documentos. Aunque haré alusión a algunos de estos cruces, sobre todo con lo ya publicado (Rolland, 2020b), queda para un trabajo futuro su síntesis. 


\section{MEdiaciones ENTRE Jóvenes Y PASAdo RECIENTE EN LA ESCUELA}

Los resultados del análisis de los vínculos de las y los estudiantes con la historia reciente argentina, a través de los sentidos que construyen en este terreno, pueden desglosarse en los siguientes cuatro bloques.

\section{Historia, ¿magistra vitae?}

Al distinguir en el análisis entre una dimensión interpretativa y otra justificativa (ver supra), se aprecian distintas relaciones entre ellas, a menudo contradictorias.

Los chicos y chicas manifiestan una noción de la historia como magistra vitae, como historia ejemplar, en tanto proporciona lecciones éticas y morales de cara al futuro, y ayuda a entender el presente, con el fin último de que nunca más se repita el terrorismo de estado, o sea, de prevenir. Justo afirma que "tenemos [la materia de] Historia porque tenemos que aprender las experiencias del pasado: las buenas para seguirlas y las malas para sacarlas de nuestras opciones". Para Diego, "[estos temas] son importantes para, después a futuro, no cometer los mismos errores" y Dona valora "estar alertas (...) frente a que vuelva a pasar".

Sin embargo, las interpretaciones, que a menudo incorporan este enfoque ético-moral en su despliegue narrativo (moralizando la historia), son mayoritariamente de tipo no histórico, sobre todo en los chicos. Es decir, no contemplan la agencia de los sujetos históricos, establecen relaciones esencialistas entre etapas (la repetida oposición ontológica entre dictadura y democracia) o de ruptura histórica, y conciben su aparición en términos naturales ( $\sin$ causas ni agentes concretos), cuando no asumen su inmanencia (como si siempre hubieran existido esas etapas), y el relato oscila característicamente entre la teleología y la circularidad (esto es: un destino prefijado y un eterno retorno a determinado punto, normalmente los gobiernos de facto o la frustración de una economía nacional). En cada caso, se indica, por ejemplo, que la dictadura es un sistema en el que se puede "caer" (Diego) (no agencia); que "por suerte esos regímenes pudieron caer y se puede volver a la democracia" (Luca) (oposición ontológica, ruptura histórica e instauración natural); que hubo "una seguidilla de regímenes no (...) democráticos" (Luca) (inmanencia y oposición ontológica); que "es casi imposible que se vuelva a producir un golpe militar" (Luca) (teleología), y que "es como un ciclo que se viene repitiendo a lo largo de todo el tiempo" (Diego) y "la economía argentina es muy... irregular, porque hay un gobierno, destruye el plan anterior y pone uno nuevo, el siguiente gobierno destruye el plan que había puesto [aquél]" (Justo) (circularidad).

Esta interpretación de tipo no histórico se apreció con más claridad en las producciones escritas (Rolland, 2020b, p. 25). Pero, de cualquier modo, contradice el objetivo de la prevención contenido en la elaboración de la historia como maestra de la vida, pues no contempla las relaciones históricas ni la intervención de los sujetos que avalarían una labor preventiva.

Esta contradicción se ve apuntalada por ciertas convergencias entre la interpretación no histórica y la justificación. El escepticismo, con el que se vincula la no agencia en esta dimensión, es una actitud recurrente, al menos en algunos alumnos; Dona acaba relativizando aquel "estar alertas" con un "no sé. ¿Qué podemos hacer (...) con respecto a lo que pasa allá, a los políticos y eso?”. Hay aquí un concepto de la política como perversión, que aparece también en Diego y Luca. A ello se suma una tensión entre el compromiso y el no compromiso al que conlleva el tema: Justo "no [tiene] ningún familiar que desapareció (...), aunque en esta escuela hubieron muchos alumnos que desaparecieron", y Dona, como Luca, señala que "no me meto mucho en la política (...) prefiero no meterme". Con todo, en este nivel reconocen ciertas relaciones históricas entre etapas, si bien bajo la clave de "las consecuencias que dejó todo este período" (Luca) y que constatan "una herida que sigue abierta en la sociedad argentina” (Diego). 


\section{El peso de la cultura escolar y el código disciplinar}

Muchos de los vínculos de los y las estudiantes con el pasado reciente (en el nivel principalmente justificativovalorativo) se deben a lo que veo como un conflicto con la cultura escolar y el código disciplinar de la materia de Historia, según los términos acuñados por Julia (1995, p. 354) y Cuesta (2007, p. 33), respectivamente.

Así pueden entenderse, primeramente, el escepticismo e incluso el rechazo de algunos, dada la desconexión respecto de sus intereses, propia del verticalismo y academicismo de la cultura escolar y de los temas y dinámicas tradicionales de la materia de Historia. Dona piensa:

Creo que no [me aporta nada estudiar este tema] (...). Porque tampoco pienso dedicarme a la historia ni nada de eso... (...). No sé... A mí no me interesa mucho la historia, pero... me tendría que interesar un poco más porque (...) el tema que a mí me interesa es el arte. Y... tiene mucho que ver con la historia (...). Eh... Por ahí, si tirara para ese lado, me interesaría más.

Diego se queja del memorismo y de las mecánicas escolares (“[el trabajo con textos en el salón] es transcribir más que aprender”) y Ana valora ciertas actividades de fuera de la escuela, como el Teatro por la Identidad, porque aborda "cosas de la actualidad". En fin, Justo se queja de que la frialdad o falta de sensibilidad en el tratamiento del tema lleva a contemplarlo "como si hubiera sido una presidencia más".

En segundo lugar, el conocimiento valorado por la institución parece estéril a la hora de emplearlo para interpretar. Dona y Justo, estudiantes con buenas calificaciones, no hacen uso de lo que, según las evaluaciones, saben, cuando se les pregunta por las posturas de distintos sectores sociales frente al golpe militar del 24 de marzo y la subsiguiente dictadura, o los hitos de la llamada vuelta a la democracia. Al respecto, Dona señala que "no sé..., no sé cómo hizo la gente para que se termine la dictadura... No sé qué hacía la gente" y Justo indica que "[lo sucedido en los 70] nos destruyó. Destruyó la economía, destruyó familias..., destruyó los derechos. Muchos trataron de responder, pero... nunca hubo una... organización en masa. Y tampoco sé si habían los medios para hacerlo. No habían medios de comunicación como ahora, que podés comunicarte con alguien que está lejos, medio rápido. Entonces las personas que trataron de... de oponerse las... las exterminaron. Las exterminaron".

En tercer lugar, el apego al o la docente podría entenderse como último refugio en este contexto, más allá de las cualidades (también reconocidas) que posea. Justo relata que "este profesor (...) es bastante bueno, (...) nos atrapa, nos hace captar la atención, nos hace participar", pues trata la "música de protesta", a propósito de la cual el estudiante apostilla significativamente: "no sé si eso está en el programa, pero... [el docente] lo hace muy bien”. ${ }^{4}$ Hay que indicar, aun así, que el apego a la docente, por ejemplo en el caso de Diego, remite también a afinidades ideológicas; su reivindicación de "el campo", con implicaciones en su valoración del gobierno previo, sumada a que declara la adscripción de sus padres al radicalismo, coincide con diversas expresiones de la docente en el mismo sentido, en una interesante convergencia entre estudiantes, familia y escuela.

El conflicto con la cultura escolar y el código disciplinar, sin embargo, varía en función de la titularidad de la escuela. En la 1 (privada) se valora positivamente la institución frente a las escuelas públicas (aquejadas presuntamente por el adoctrinamiento ideológico y las movilizaciones sindicales), mientras en la Escuela 2 (pública) hay una falta de identificación con el colegio y un desapego respecto de la cultura escolar. La mencionada crítica de Diego hacia el memorismo y la monotonía parece omniabarcativa:

Yo creo que no se fomenta la creatividad en..., en..., en los colegios de la Argentina (...). [P]or eso se utiliza más la memoria (...). Es como repetir un verso de memoria, o sea, leer algo, estudiarlo y después te lo olvidás. Y así es como aprobás toda la escuela primaria y secundaria.

Pero en otros momentos, como veremos, alude explícitamente a lo que sucede en "un colegio estatal”. Esta alusión connotada a la educación pública se aprecia también en la valoración positiva que hace Luca de su escuela y la docente: 
Por suerte la profesora nos dio varios textos (...). [N] unca nos bajó, digamos..., no sé si sabrás lo que es bajar línea política (...). Bueno, generalmente cuando se trata de estos temas, se suele..., en otras escuelas o en general, de distintos temas, se suele bajar mucha línea política, pero por suerte (...) lo pudimos estudiar de manera más libre.

En ello coinciden también con las apreciaciones de su docente y la dirección, cuando señalan como problema central del país a "la educación".

Este repliegue hacia la institución se aprecia en otras situaciones, cuando algunas estudiantes comentan cómo ha sido su relación con compañeros de escuelas públicas en las sesiones preparatorias del Encuentro Provincial para el $9^{\circ}$ Encuentro Nacional del Parlamento Juvenil del Mercosur de 2018. Y directiva, docentes y estudiantes coinciden, en distintas oportunidades, en señalar como problema central del país a "la educación".

En la Escuela 2, por el contrario, al rechazo de Dona se suman la queja de Justo respecto de que sea sólo en $6^{\circ}$ cuando se trate el tema y la desaprobación respecto de la conmemoración del 24 de marzo: "al día siguiente te olvidás de que estuviste ayer en un acto". 5 A ello se añade la patente actitud refractaria frente a la cultura escolar constatada en las producciones escritas (ver Rolland, 2020b, p. 28, fig. 7).

\section{Las relaciones entre pares encarnadas en los sentidos sobre el pasado reciente}

Los vínculos con el pasado reciente en las dos dimensiones citadas incorporan también el tipo de relaciones que mantienen los pares: son uno de los vehículos de muchas de sus pugnas y afinidades, sobre todo de tipo ideológico. La clave más persistente de estas relaciones es la confrontación, a veces callada, otras veces abierta y otras negada; en cada caso, correspondientes a Dona, Ana y Diego y Luca, las narraciones remiten a una situación de aislamiento, a una afirmación personal a través de la polémica y a una oclusión para apuntalar determinados consensos impuestos (a nivel institucional y social).

Dona valora negativamente el tratamiento del tema en el salón, por su parcialidad, bajo la rúbrica de "la dictadura de lo políticamente correcto":

No se puede evitar enseñarlo así... (...), porque todos piensan así (...). Se ponen como de un lado sólo (...), [del lado de] los que defienden al pueblo... y... se cierran como en un idea, como... los de izquierda o (...) [las] que están en el movimiento feminista (...). Y también eso se viraliza y terminan hablando personas que no tienen ni idea (...). [Y] o conozco una sola interpretación

(...). Y por ahí si decís que..., que estás de acuerdo con lo que dice [Videla], eh..., te tratan como..., no sé, cualquier cosa. Es la dictadura de lo políticamente correcto.

Nótese, sin embargo, que en su relato hay una neta oposición entre ella y el resto ("ellos"). Esto sugiere que se trata de una apreciación en la que la percepción de un problema real que discutimos al final está teñida por las relaciones que tiene con sus pares. Dona me ha parecido una alumna retraída, sentada en primera fila, aparte del resto, abstraída en sus pensamientos y aparentemente focalizada en el docente. En la entrevista comenta que relaciones con los demás no tiene "ninguna (se ríe) (...). Es como que me mantengo alejada", aunque "si tengo que hacer un grupo ahí en el salón no tengo problema... Participo", pero "fuera del aula no".

Ana también aprecia parcialidad por parte de sus compañeros, además de la docente ("[su] ideología era la misma, o parecida a la ideología de... los grupos que tomaron el poder (...). [E]lla tiene esa postura”). Aquí se ve que en algunos casos las relaciones conflictivas entre pares dan forma a lo que manifiestan (o dejan de manifestar) sobre el pasado reciente, por más que puedan estar influidas a su vez por ello:

[T]ambién el curso (...) está dividido, pero capaz la gente que opina más como yo, como que se queda más calladito (...). Como que son más tímidas. O... o no se quieren pelear con algún compañero. Porque yo... o sea, hay unos compañeros que son muy como... como que... se enfrentan demasiado (...). Y capaz como que les da miedo de pelearse así.

Ana, en cambio, no cede, de modo que en su caso la confrontación es manifiesta. Y emplea premeditadamente el tema para socializar, sin demasiadas consecuencias, por lo demás. Reconoce que: 
debato con todos. Ya me viste vos, que... (...). Yo digo: «mirá, no me parece». Y hablo. Y yo... La profe me debe matar... [se ríe]. Yo todo el día ahí, levanto la mano y digo: «mmm...», no sé, tal cosa (...). Yo creo que después, o sea, [a aquellos con los que discuto] se les pasa. Se preocupan por otra cosa y ya se olvidaron (...). No nos llevamos

En el caso de Diego y Luca, la valoración positiva de la cursada está ocultando determinados conflictos bajo el manto del consenso (en torno al significado de la dictadura). La "postura" de la docente y sus afirmaciones sobre "la subversión", junto con las polémicas que efectivamente se desatan, como veremos seguidamente, sugieren que no existe tal consenso y de ese modo con las palabras de Diego y Luca se produce una oclusión del conflicto. Para Diego,

aspecto positivo fue... (...) -la profesora Fernández siempre lo hace- contrastar dos autores (...). Entonces te da la posibilidad de tener distintos puntos de vista (...). [Sin embargo,] a nivel de opiniones, yo creo que acá no hay tanta heterogeneidad (...), porque acá se está hablando de la dictadura específicamente; entonces, no creo que... alguno de los dos opine que, que está bien, digamos. Es muy extremista decir que está bien (...). [Y entre nosotros] lo que es la dictadura en sí no hay mucha diferencia de opiniones, porque todos, obviamente, creemos que fue algo malo.

En todos estos casos los contextos extraescolares están desempeñando un papel importante; la familia o los pares (de fuera de la escuela) son, si no fuente, al menos vector de confrontación y los sentidos sobre el pasado (también en un plano interpretativo) canalizan las lealtades correspondientes. A Dona es su pareja (un año mayor y ya egresado en la misma escuela) quien le habla de esa presunta dictadura, mientras que Ana considera que "lo que yo vivo con mi familia, digo, tengo este pensamiento y... y como que estoy tan, más segura”. Diego, por su parte, reconoce polémica en aquellos temas más conectados con sus padres (radicales): "Lo que sí hay diferencia de opiniones, y ahí es cuando se torna más... caliente el tema (...), es cuando se habla o de Perón o de Alfonsín”.

\section{4. ¿Qué hacer ante una crisis total?}

La investigación planteó en las entrevistas un dilema para analizar las actitudes políticas con perspectiva histórica: partíamos de una hipotética situación de crisis total, cuya definición particular y partidista sirvió en 1976 para avalar, ante amplios sectores, el golpe militar, al hilo de la construcción del "enemigo interno" en los años previos (Franco, 2012), y los estudiantes proponían cómo creían que debían o podían actuar ellos y el Estado ante ella.

El referente histórico principal que emplearon para dar sentido a esa situación fue la dictadura de 1976-1983, aunque también aludieron a los años 2001 y 1930 y al nazismo y la Segunda Guerra Mundial. La clave predominante para entender aquélla, que determina, a su vez, la representación de la crisis total, es el horror, común a otros contextos escolares y sociales (Kriger, 2011).

Sin embargo, el papel que se atribuyen varía nuevamente en función de la escuela. En la 2 abunda la impotencia, mientras en la 1 se aprecia una cierta determinación para la resistencia. Así, en relación con su escepticismo al justificar el tratamiento del pasado reciente "para prevenirse", Dona apunta que "como individuo, no puedo hacer nada (se ríe) (...) y [de otra manera] creo que... tampoco (...). Igual, más que nada porque, como dije, no sé si la influencia mucho la que pasa..., los movimientos sociales y eso a la gente que toma las decisiones"; además, no se puede escapar al cumplimiento de órdenes, como muestra lo aprendido con la Ley de Obediencia Debida ("si no cumplías algo de que te decían uno de los grandes del gobierno... eran capaces de matarte"). En consecuencia, Justo se iría "al sur" y Dona aboca al autoaniquilamiento: "[se ríe] No sé. Me suicidaba”, y más adelante plantea también que "yo me voy del país”.

En la Escuela 1, en cambio, Diego se propone "emitir mi opinión, por ejemplo, o, por qué no, adherirme a alguna marcha en contra de ese régimen dictatorial"; Ana manifiesta que "seguro que me haría llegar a mis amigas" e imagina una labor de resistencia con determinados referentes históricos (la música de protesta de 
Charly García), y Luca "buscaría una estrategia”, amparándose en que "el pueblo se va a rebelar”. Es llamativo el contraste entre estas afirmaciones de Diego y Luca y el escepticismo en sus narraciones.

De las lógicas que rigen la actuación del Estado ante la crisis total destaca la racionalidad instrumental, que junto a otras aparece recurrentemente en la interpretación y la justificación del tema (Rolland, 2020b: 22-3). En función de ella, cualquier actuación se encuadra en la fría evaluación de la relación entre medios y fines, de modo que el terrorismo de Estado se descalifica por su ineficacia o sus elevados costes. Para Diego, "[los militares] creían que el derrocamiento del presidente era la solución (...), pero a la larga no beneficia en nada al país (...). Entonces es como que no compensa una cosa con la otra”.

Las propuestas de las y los estudiantes son medidas a largo plazo (estructurales) y no represivas. Ana nos cuenta:

[Y]o le digo a la profe: «o sea, bueno, yo no justifico que rompan cosas [en las marchas], qué se yo, pero la gente tiene bronca y necesita comer, necesita alimentarse», no sé. Entonces (...) el presidente tendría que... volcarse a... a lo que le reclama el pueblo (...), escuchar los reclamos.

Las medidas propuestas representan gran complejidad, aunque se reducen a dos generales: limitar el poder militar y policial, e incidir sobre el sistema educativo. Las primeras se nutren de la percepción de la última dictadura como un periodo de arbitrariedad y descontrol, de modo que, con una lógica utilitarista, se requeriría una "administración" correcta. Para Dona, actualmente "la policía no es tan violenta, creo. Antes no había control... Igualmente hace poco pasó que hubo mucha represión policial en una manifestación. Pero eso fue por una mala administración de la policía”. Las medidas relativas a la educación ahondan en lo relevado más arriba; como expresa Luca:

Si uno piensa en educación y lo conecta con las escuelas y uno asocia con todo lo que ha pasado en este último tiempo de... los paros que hay de los docentes, que no dan clases (...), [ve que todo esto lleva a] que..., no sé, el nivel académico sea mucho más bajo (...), de las escuelas... generalmente..., sí, de las escuelas públicas (...). Hasta el día de hoy siguen habiendo paros (...). Nosotros tenemos [clase] porque es privada y no se adhieren a ese paro.

Se trata de un momento (todo el 2018), en efecto, de crispación por las paritarias, aunque no se discute que su propia docente es pagada por la Provincia y por algún motivo no se moviliza. Lo que cuenta, de nuevo, es la contraposición con la pública.

Es precisamente el tema de la protesta social, junto con el muy candente (desde hace años en la ciudad y en todo el país) de la "seguridad", el que hace aflorar la última cuestión para tratar aquí. Varios estudiantes realizan determinados deslindes que manifiestan una actitud política que podría ser favorecedora de medidas excepcionales próximas a o propias del terrorismo de Estado (como las desplegadas antes y durante la dictadura de 1976). En efecto, distinguen entre una movilización "pacífica" y una "violenta", entre "robos y cortes", o se quejan de que en la dictadura se metiera a "todos en la misma bolsa” en lugar de distinguir a "personas normales" de "los ladrones" u otros criminales. Estos deslindes avalan un tratamiento punitivo diferencial: normal en un caso, excepcional en otro. Para Diego, " $[\mathrm{u}]$ na cosa es una movilización pacífica, por ejemplo... ¿Qué represión le podés hacer a una movilización pacífica, digamos? El problema se da, más que nada, creo yo, entre lo que es... la policía y los manifestantes, cuando hay violencia”. Y Justo hace

una gran diferencia entre robos y cortes. La gente sale a cortar la calle (...) porque hay algo que le duele personalmente, que sabe que es injusto. Pero la gente que sale a robar, no la justifico para nada. Es un ladrón matando a otro ladrón, el militar matando a... a un ladrón (...). [L] a manera que tiene uno de pagar las cosas malas que hizo es hacer nada el resto de su vida (...), cadena perpetua.

\section{ELEMENTOS DE UNA EDUCACIÓN PARA LA EMANCIPACIÓN}

Con este trabajo he intentado explorar los complejos vínculos entre estudiantes y pasado reciente en dos escuelas, a propósito de los múltiples intercambios entre distintas temporalidades. El fin último ha sido 
realizar un diagnóstico realista de este caso particular para trascender los juicios sombríos sobre los trabajos escolares de la memoria y potenciar la educación para la emancipación en relación con el pasado reciente (Rolland, 2020a).

Concretamente hemos apreciado, en primer lugar, una importante contradicción entre las dimensiones interpretativa y justificativa de las narraciones, acaso por la separación entre principios y prácticas propia del positivismo. Ante ello, se pueden plantear tres caminos. Por un lado, una educación emancipadora aspiraría a explicitar y vincular objetivos e interpretaciones, cualesquiera sean, más allá de su corrección política (De Amézola, 2018a, p. 32). Se trataría de provocar la confrontación política entre ellos, en términos agonistas, esto es, oponiendo posturas o proyectos al tiempo que se mantiene la "asociación política" (Mouffe, 2005, pp. $7,25,52)$. Ese ser "extremista" que Diego censura debe aflorar para enfrentarlo; la abdicación de la política, bajo el manto de la moral, típica de la pospolítica, no hace más que imponer falsos acuerdos y, con ellos, programas bien decantados sin ningún tipo de discusión (González, 2010).

Por otro lado, hay que trabajar las relaciones entre pasado(s) y presente(s), en términos de divergencia y ruptura, pero también de convergencia y continuidad. Son estas últimas las que se vinculan de modo más realista con un proyecto de prevención (Mudrovcic, 2010, pp. 343-5). Esto supone insistir, frente a las interpretaciones no históricas y utilitaristas, en que el terrorismo de Estado no es ajeno a las sociedades en que prolifera (como error, desvío, descontrol, complot o destino prefijado), sino que se vincula intrínsecamente con ellas y sus proyectos de ingeniería social (Bauman, 2016). Para ello sería crucial profundizar en los modos en que se gestan históricamente los procesos históricos, en cuanto a las "normalidades" (Calveiro, 2014, p. 149), las "fractura[s]" (Caviglia, 2006, p. 60) y los "enemigos" de la sociedad (Franco, 2012).

A esto se añade el trabajo de empoderamiento de los sujetos, tanto en el pasado (a la hora de explorar la acción individual y colectiva) como en el presente (para reconocer y discutir los límites y posibilidades de la gente). En este último sentido, es fundamental analizar cómo se vinculan las y los jóvenes con la política, más allá de epítetos culpabilizadores sobre la "despolitización” (Kriger, 2008, 2014; Núñez, 2010; Bruno y Barreiro, 2014; Garriga et al., 2018).

En segundo lugar, he caracterizado una serie de elementos de la cotidianidad de la vida escolar que explican los vínculos con el pasado reciente (sobre todo en cuanto a la valoración de su abordaje). Aquí son centrales las diferentes situaciones de transmisión. Tanto el contexto académico escolar, con sus "expectativas normativas", como la "situación de entrevista" son respondidos activamente por los estudiantes, por ejemplo con relatos sintéticos marcados por la identificación (Legarralde 2017, p. 228) y con el rechazo explícito o implícito del tema. Junto a ello figuran las elaboraciones de miedos, anhelos y lealtades, que remiten a una miríada de relaciones entre los pares, a menudo conflictivas e imbricadas con el mundo extraescolar. Finalmente, en un sentido más estructural, intervienen una variedad de factores: el socioeconómico (De Amézola, 2018b, p. 144), la edad y el género (Mariño, 1999, p. 92; Pereyra, 2007, p. 206-11, gráficos 2, 3, 4 y 6) y la familia (Jabaz y Lozano, 2001, pp. 101, 103; Nobile, 2004, p. 81; Legarralde, 2017, pp. 195, 240 , tabla 4); la titularidad del centro debe considerarse igualmente para explicar la actitud de impotencia o de resistencia frente a un futuro hipotético, en relación quizás con el desapego en la Escuela 2 y el anclaje en la 1 (Rolland, 2020b, p. 30).

La intervención de todos estos factores nos muestra que la historia enseñada a menudo influye muy débilmente en los chicos y chicas frente a lo que han aprendido en otros entornos (Cerri y De Amézola, 2010, p. 20), pero eso no debe minimizar el papel de la escuela (y no sólo por lo mencionado sobre las efemérides en la nota 3); al fin y al cabo, los sentidos que he tratado aquí se han generado en ella, de modo que, si el contexto no es un mero marco, habrá que considerar su intervención activa: las relaciones (de conflicto, armonía, expectativa, temor) entre los estudiantes (y de éstos con los docentes y la institución) canalizan los significados dados al pasado y éstos, al mismo tiempo, alimentan esas relaciones. No se trata, pues, tanto de establecer cuál es el factor determinante en la constitución de los sentidos sobre el pasado (ni mucho menos 
la primacía de la escuela), sino los modos en que los distintos factores actúan en el dominio escolar, entendido como trama real concreta.

Por todo ello, una educación para la emancipación no puede evitar abordar y transformar las relaciones que mantienen y mantenemos los sujetos con la cultura escolar y los códigos pedagógicos y profesionales (Cuesta, 2007, pp. 24, 46). Esto incluye reflexión y actuación en cuanto a la cultura, sentido y pasado de la escuela (Dussel y Pereyra, 2006; Raggio 2014, pp. 135, 141), y a sus relaciones con la política, particularmente el conflicto (Pappier y Morras, 2008; Raggio 2017). A esto se añade la comprensión de los procesos de subjetivación en la experiencia diaria de la escuela, especialmente en un contexto de anomia (Dubet y Martuccelli, 1998; Tiramonti, 2005; Weiss 2009).

En tercer y último lugar, he observado cómo las representaciones sobre el pasado (referido fundamentalmente a la última dictadura), bajo la clave del horror, articulan sentidos sobre el futuro que condicionan presumiblemente la intervención de los jóvenes en la vida social, aunque la relación entre aquéllos y ésta es compleja (Carretero y Kriger, 2006, p. 22).

Así, de lo relevado, acaso lo esencial es que, bajo las medidas no represivas y a largo plazo, subyacen en algunos casos ciertos deslindes en torno a determinados sujetos colectivos. Son deslindes que avalarían medidas de excepción o políticas terroristas, dado que se amparan en una contraposición entre inocentes y culpables; la esencia de éstos, su culpabilidad, los hace "merecedores" de tales castigos (Calveiro, 2014, pp. 132-5, 162). Aquí rige, además, la racionalidad instrumental, en tanto, en algunos casos, se justifica cualquier medio con tal de lograr el fin (el mantenimiento del "orden" o evitar la crisis total), sin considerar otros elementos. En una compleja relación de intercambio de temporalidades, está interviniendo la narrativa humanitaria (Jelin, 2007, p. 328). Pero lo importante es que ésta en parte marca, a su vez, ciertas representaciones sobre seguridad y protesta social hoy día, al reclamar "mano dura" contra "chorros" o "violentos" (por ejemplo, "piqueteros") (Dandan, 2011), negándoles su entidad como sujetos de derecho. Es este juego de temporalidades el que da verdadero sentido al trabajo con la historia y debe cualificarse empíricamente, aunque algunos lo han mencionado ya (Mariño, 1999, pp. 87, 88; Jabaz y Lozano, 2001, p. 118; Nobile, 2004, pp. 85-6; Pereyra, 2007, pp. 180-1, 223-4; Higuera, 2010, pp. 97, 98; Pappier, 2016, pp. 97, 130, 169-170, 189).

Por ello, en la educación para la emancipación, lo que enseñamos y aprendemos sobre el pasado reciente entraña, en la práctica, soluciones particulares (y revisables) sobre problemas ético-morales, de modo que hay que indagar, desde la pedagogía y la investigación educativa, en las actitudes y valores políticos movilizados. En conjunto, si el conocimiento o la conciencia no bastan para prevenir no es sólo porque la interpretación y la justificación estén desarticuladas, o porque ese conocimiento se mantenga extraño a los intereses y relaciones de los y las jóvenes, ni siquiera porque se limite a lo cognitivo, sino porque no es histórico en un sentido profundo, esto es, porque sigue escindido y fracturado. Al fin y al cabo, nuestro oficio como historiadores y docentes es analizar y determinar los procesos que convergen y divergen con el presente para anclar lo más sólidamente posible nuestros proyectos de futuro.

\section{REFERENCIAS}

Adorno, T.W. (1998). Educación para la emancipación. Conferencias y conversaciones con Hellmut Becker (1959-1969). Madrid: Morata.

Alonso, F., Montenegro, L. y Pini, V. (2008). La entrevista: testimonios, trayectorias y prácticas. De Signos y Sentidos, 7,23-37.

Bauman, Z. (2016). Modernidad y Holocausto. Madrid: Sequitur.

Born, D. (2010). Las representaciones de la última dictadura militar. Los textos escolares de Historia en el nivel Secundario de la Ciudad de Buenos Aires, 1976-2009 [Tesis de Maestría], FLACSO. 
Bracchi, C. y Paulozzo, M. (2012). Diseño Curricular para la Educación Secundaria 6o año: Orientación Ciencias Sociales. La Plata: Dirección General de Cultura y Educación de la Provincia de Buenos Aires.

Bruno, D. y Barreiro, A. (2014). La política como representación social. Psicología Política, 48, 69-80.

Calveiro, P. (2014). Poder y desaparición. Los campos de concentración en Argentina. Buenos Aires: Colihue.

Carretero, M. y Kriger, M. (2006). Enseñanza de la historia y formación ciudadana: representaciones del pasado y proyecciones del futuro de los jóvenes argentinos. Espacios en blanco. Revista de Educación, 16, 17-46.

Castorina, J.A. (2006). Un encuentro de disciplinas: la historia de las mentalidades y la psicología de las representaciones sociales. En: M. Carretero, A. Rosa y M.F. González (Comps.), Enseñanza de la historia y memoria colectiva (pp. 73-90). Buenos Aires: Paidós.

Caviglia, M. (2006). Dictadura, vida cotidiana y clases medias: una sociedad fracturada. Buenos Aires: Prometeo.

Cerri, L.F. y De Amézola, G. (2007). Los jóvenes brasileños y argentinos frente a la Historia. Una investigación intercultural sobre la enseñanza y el aprendizaje de la Historia. Revista de Teoría y Didáctica de las Ciencias Sociales, 12, 31-50.

Cerri, L.F. y De Amézola, G. (2010). El estudio empírico de la conciencia histórica en jóvenes de Brasil, Argentina y Uruguay. Didáctica de las Ciencias experimentales y sociales, 24, 3-23.

Chesneaux, J. (1984).¿Hacemos tabla rasa del pasado? A propósito de la historia y de los historiadores. Madrid: Siglo XXI.

Cuesta, R. (2007). Los deberes de la memoria en la educación. Barcelona: Octaedro.

Dandan, A. (2011). El estigma sobre la militancia todavía tiene vigencia. Entrevista a Emilio Crenzel. Página/12, 31 de julio de 2011.

De Amézola, G. (2018a). ¿Qué saben los estudiantes secundarios de la última dictadura? Fortalezas y debilidades de la formación de ciudadanos en las clases de Historia de escuelas secundarias de la ciudad de La Plata. Clío \& Asociados. La Historia enseñada, 27, 30-42.

De Amézola, G. (2018b). Veinte años de dictadura. La enseñanza de la última dictadura militar (1976-1983) en las escuelas secundarias de Argentina. En G. De Amézola y L.F. Cerri (Coords.), Los jóvenes frente a la Historia: Aprendizaje y enseñanza en escuelas secundarias (pp. 133-151). La Plata: UNLP-FaHCE.

De Amézola, G. y Cerri, L.F. (Coords.) (2018). Los jóvenes frente a la Historia: Aprendizaje y ensen\#anza en escuelas secundarias. La Plata: UNLP-FaHCE.

Dubet, F y Martuccelli, D. (1998). En la escuela. Sociología de la experiencia escolar. Buenos Aires: Losada.

Dussel, I. y Pereyra, A. (2006). Notas sobre la transmisión escolar del pasado reciente de la Argentina. En M. Carretero, A. Rosa y M.F. González (Comps.), Enseñanza de la historia y memoria colectiva (pp. 253-275). Buenos Aires: Paidós.

Duveen, G. y Lloyd, B. (2003). Las representaciones sociales como una perspectiva de la psicología social. En J.A. Castorina (Comp.), Representaciones sociales. Problemas teóricos y conocimientos infantiles (pp. 29-39). Barcelona: Gedisa.

Fontana, J. (1999). Historia. Análisis de pasado y proyecto social. Barcelona: Crítica.

Franco, M. (2012). Un enemigo para la nación: orden interno, violencia y "subversión", 1973-1976. Buenos Aires: FCE.

Franco, M. y Levin, F. (2007). El pasado cercano en clave historiográfica. En M. Franco y F. Levin (Comps.), Historia reciente. Perspectivas y desafios para un campo en construcción (pp. 31-65). Buenos Aires: Paidós.

Garriga, M.C., Pappier, V. y Morras, V. (2010). Los jóvenes entre la historia y la política. Primeras aproximaciones a las representaciones de la democracia, los gobiernos militares y la participación política de alumnos de la escuela secundaria. Clío \& Asociados. La Historia enseñada, 14, 1-10.

Garriga, M.C., Morras, V. y Pappier, V. (2018). La conciencia histórica en jóvenes de la Provincia de Buenos Aires. En G. De Amézola, G. y Cerri, L.F. (Coords.), Los jóvenes frente a la Historia: Aprendizaje y enseñanza en escuelas secundarias (pp. 83-100). La Plata: UNLP-FaHCE.

González, A. (2010). Contra la pospolítica. Arqueología de la Guerra Civil española. Revista de Antropología, 22, 9-32.

González, M.P. (2014). La historia reciente en la escuela: saberes y prácticas docentes en torno a la última dictadura. Los Polvorines: UNGS. 
Guelerman, S.J. (2001). Escuela, juventud y genocidio. Una interpretación posible. En S.J. Guelerman (Comp.), Memorias en presente. Identidad y transmisión en la Argentina posgenocidio (pp. 35-64). Buenos Aires: Norma.

Guglielmucci, A. (2013). La consagración de la memoria. Una etnografia acerca de la institucionalización del recuerdo sobre los crimenes del terrorismo de Estado en Argentina. Buenos Aires: Antropofagia.

Hammersley, M. y Atkinson, P. (1994). Etnografia. Métodos de investigación. Barcelona: Paidós.

Higuera, D.M. (2010). La escuela ante la transmisión del pasado reciente argentino: sentidos comunes, dilemas de la representación y los desafios del presente. Buenos Aires: Libros libres.

Hobsbawm, E. (1997). On History. Nueva York: New Press.

Jabaz, M. y Lozano, C. (2001). Memorias de la dictadura y transmisión generacional: representaciones y controversias. En S.J. Guelerman (Comp.), Memorias en presente. Identidad y transmisión en la Argentina posgenocidio (pp. 97-131). Buenos Aires: Norma.

Jelin, E. (2007). La conflictiva y nunca acabada mirada sobre el pasado. En M. Franco y F. Levin (Comps.), Historia reciente. Perspectivas y desafios para un campo en construcción (pp. 307-40). Buenos Aires: Paidós.

Jelin, E. y Lorenz, F.G. (2004). Educación y memoria: entre el pasado, el deber y la posibilidad. En E. Jelin y F.G. Lorenz (Comps.), Educación y memoria. La escuela elabora el pasado (pp. 1-10). Madrid: Siglo XXI.

Julia, D. (1995). La culture scolaire comme objet historique. Paedagogica Historica: International Journal of the History of Education, 31(1), 353-382.

Kriger, M. (2008). Historia, identidad y proyecto en la Argentina post-2001. Las representaciones de los jo\#venes sobre la política y la ciudadanía. Clío \& Asociados. La Historia enseñada, 12, 123-141.

Kriger, M. (2011). La enseñanza de la historia reciente como herramienta clave de la educación política. Persona y Sociedad, 15(3), 29-52.

Kriger, M. (2014). "Politización juvenil en las naciones contemporáneas. El caso argentino. Revista Latinoamericana de Ciencias Sociales, Niñez y Juventud, 12(2), 583-596.

Legarralde, M. (2012). Estudios sobre la transmisión escolar de las memorias de la última dictadura militar. Archivos de Ciencias de la Educación, 6(6). https://www.archivosdeciencias.fahce.unlp.edu.ar/article/view/Archivos06a09.

Legarralde, M. (2017). Combates por la memoria. La transmisión de la última dictadura militar en las escuelas secundarias de la provincia de Buenos Aires (2008 - 2013). Tesis doctoral, UNLP.

Lorenz, F.G. (2006). El pasado reciente en la Argentina: las difíciles relaciones entre transmisión, educación y memoria. En M. Carretero, A. Rosa y M.F. González (Comps.), Enseñanza de la historia y memoria colectiva (pp. 277-95). Buenos Aires: Paidós.

Mariño, M. (1999). Los jóvenes y el pasado de los argentinos: conciencia histórica y futuros imaginados. En A. Puiggrós (Comp.), Los limites de la educación. Niñosy jóvenes del fin de siglo (pp. 51-96). Rosario: Homo Sapiens Ediciones.

Mouffe, Ch. (2005). On the political. Londres: Routledge.

Mudrovcic, M.I. (2010). Novedad, progreso y desaceleración: las tensiones político-temporales, 1810-1910-2010. En W. Ansaldi, P. Funes y S. Villavicencio (Eds.), Bicentenario. Otros relatos (pp. 329-346). Buenos Aires: Ediciones del Puerto.

Nobile, M. (2004). La memoria colectiva de los adolescentes de la ciudad de La Plata sobre la última dictadura militar [Trabajo final de grado]. UNLP.

Núñez, P. (2010). Política y poder en la escuela media. La socialización politica juvenil en el espacio escolar [Tesis doctoral]. UNGS.

Pappier, V. (2016). La historia reciente en las aulas de nivel secundario. Prácticas escolares en torno a la última dictadura argentina [Tesis de maestría]. UNLP.

Pappier, V.y Morras, V. (2008). La construcción de la memoria en la escuela. Una mirada a los actores y conflictos que genera la conmemoración del 24 de marzo. Clío \& Asociados. La Historia enseñada, 12, 173-192.

Pereyra, A. (2007). La relación de los adolescentes con la historia reciente de Argentina. Un estudio exploratorio de la conciencia histórica entre estudiantes de escuelas medias públicas de la ciudad de Buenos Aires [Tesis doctoral]. FLACSO. 
Raggio, S. (2014). Argentina: el pasado reciente y su gestión en la escuela ¿Hacia una nueva pedagogía?. En F. González y B. Areyuna (Comps.), Pedagogía, historia y memoria critica. Una mirada educativa a los discursos y lugares de la memoria (pp. 115-43). Santiago de Chile: Facultad de Pedagogía de la Universidad Academia de Humanismo Cristiano.

Raggio, S. (2017). Transmisión de la memoria: la experiencia en el encuentro con Otros. El largo proceso de institucionalización de la memoria en la escuela. Aletheia. Revista de la Maestría de Historia y Memoria de la FaHCE, 7(14). https://www.aletheia.fahce.unlp.edu.ar/article/view/ATHv7n14a09.

Rolland, J. (2020a). Deberes de memoria en las escuelas. Una revisión crítica para la construcción democrática a partir del caso argentino. Enseñanza de las Ciencias Sociales, 19, 79-89.

Rolland, J. (2020b). Mediaciones entre jóvenes y pasado reciente. Un análisis a partir de sus producciones escritas en dos escuelas de La Plata (Buenos Aires, Argentina). Clio \& Asociados. La historia enseñada, 30, 17-33.

Rüsen, J. (2007). How to make sense of the past -salient issues of Metahistory. The Journal for Transdisciplinary Research in Southern Africa, 3(1), 169-221.

Tiramonti, G. (Comp.) (2004). La trama de la desigualdad educativa. Mutaciones recientes en la escuela media. Buenos Aires: Manantial.

VVAA (2015). Las representaciones de los jóvenes sobre el pasado reciente. Relevamiento nacional. Buenos Aires: Ministerio de Educación, Presidencia de la Nación.

Weiss, E. (2009). Jóvenes y bachillerato en México: el proceso de subjetivación, el encuentro con los otros y la reflexividad. Propuesta Educativa, 32, 83-94.

Wertsch, J. (1998). La mente en acción. Buenos Aires: Aique.

Zysman, N. (2015). De la "subversión marxista" al "terrorismo de Estado". Representaciones de la última dictadura militar en las narrativas históricas de la escuela media argentina (1983-2009). Córdoba: Editorial Universitaria Villa María.

\section{Notas}

1 Trabajo realizado en el marco de una beca posdoctoral financiada por el CONICET (Argentina), dirigida por Mario Carretero (Facultad Latinoamericana de Ciencias Sociales-Universidad Auto\#noma de Madrid) y vinculada al Proyecto PICT-2016-2341.

2 Los nombres son ficticios, para garantizar el anonimato.

3 Hay que señalar que, en la Provincia de Buenos Aires, si bien se contempla cubrir la segunda mitad del siglo XX en América Latina en $5^{\circ}$ año, en estas dos escuelas (y en otras) no se consigue hacerlo, de modo que sólo las y los estudiantes de la orientación de Ciencias Sociales y Arte los pueden abordar recién en $6^{\circ}$ (junto con el proyecto de investigación prescrito). Téngase en cuenta, aun así, que las efemérides vinculadas con el pasado reciente suelen comprometer a todos los años (veáse Pappier y Morras, 2008, con bibliografía de referencia). Además, las bibliotecas ofrecen distintos materiales sobre el tema (en el caso de la Escuela 2, esos materiales se destacan en un espacio específico rotulado "Historia argentina reciente", con una balda dedicada al "Terrorismo de estado" y "Malvinas").

4 En el Diseño Curricular provincial para $6^{\circ}$ año de Secundaria tan sólo aparece el "rock nacional" como uno de los temas para el "proyecto de trabajo" de la Unidad 2 (Bracchi y Paulozzo, 2012: 43). Por otro lado, el tema aparece reiteradamente por iniciativa de docentes y estudiantes, por ejemplo en el mismo 2018 con motivo del 24 de marzo (conferencia "Rock y dictadura”, a cargo de Juan Ignacio Provéndola, 26 de marzo de 2018, Colegio Nacional Rafael Hernández).

5 Recoger cómo se vivió el 24 de marzo en esta escuela requeriría extendernos más allá de lo planteado aquí, pero téngase en cuenta que la única iniciativa institucional en este caso fue distribuir una fotocopia a cargo del vicedirector. 